\title{
A Summary of Educational Scholars' View on Educational Purpose during the Period of the Republic of China
}

\author{
Naiyue Sun*, Cuilan Zhao \\ Qingdao University, Qingdao 266071, Shandong Province, China \\ *Corresponding author: Naiyue Sun, $865839071 @$ qq.com
}

\begin{abstract}
By using literature data analysis, taking the views of educational scholars during the Republic of China as an entry point, selecting representative educational scholars from that period, studying the educational goals of those educational scholars, as well as summarizing and refining their educational concepts, it has been found that the focus was on the cultivation of a sound personality, the development of spiritual values, the cultivation of social responsibility, as well as the cultivation of national consciousness. These four aspects are consistent with the comprehensive development demands by the educational purposes of modern countries in terms of moral, intellectual, physical, artistic, and labor; they provide new supplements and impetus for the current educational purposes to cultivate effective people and develop socialism with Chinese characteristics.
\end{abstract}

Keywords: Republic of China; Educational scholars; Educational goals

Publication date: November 2021; Online publication: November 30, 2021

\section{Introduction}

The period of the Republic of China was a critical period of social transformation in modern China. During this period, the educational circle was very active. The educational thought and practice of scholars at that time reflected the changes of modern education in modern China from the side. Their educational thoughts still inspire and have reference significance in today's education.

\section{Methods}

By analyzing the first-hand data of education scholars during the Republic of China, this study mainly uses literature data analysis and the method of dimensional division to understand the scholars' educational goals and concepts comprehensively and accurately as well as to summarize and classify the literatures, respectively, in order to examine the ideas of different scholars about the educational purpose of the Republic of China, summarize the characteristics of the era, and achieve the effect of learning from the past.

\section{Concept definition}

\subsection{Educational scholars}

In order to understand the concept of educational scholars, it is necessary to first understand the concept of scholars. According to the interpretation of the Chinese dictionary, "scholars" belong to a sociological concept, which can be distinguished between a broad sense and a narrow sense. In a broad sense, a "scholar" refers to a person who has a certain level of knowledge and is able to express ideas in certain fields, put forward opinions, as well as lead the trend of social culture. A "scholar" in the narrow sense refers to a 
person who specializes in the study of a certain academic system. The types of scholars mainly include thinkers, philosophers, jurists, writers, historians, and theoretical or academic experts of various cultures. It can be seen that "educational scholars" are one of the types of "scholars." The definition of "educational scholars" in this article also include people who have a certain leading role in their society with a certain academic influence.

\subsection{View on educational purpose}

The view on educational purpose mainly represents the views of the advocates on the integrity and fundamentality of the educational purpose. It hides the philosophical views and cultural values behind the advocates. Therefore, the operative definition of the view on educational purpose in this article is set as an individual's fundamental understanding and overall view of the normative educational purpose based on his or her own experience. It is the individual's interpretation and thinking of the educational purpose, which reflects behind it the values, philosophy, and world outlook of that specific individual.

\section{Literature review}

Based on the National Digital Library of China and the National Newspaper Index website, a literature search for educational scholars during the Republic of China was carried out, and the literatures of each scholar were divided into different dimensions. The main research contents of the scholars are discussed below.

\subsection{Develop healthy people}

\subsubsection{From the perspective of survival and health}

Athletic ability refers to the ability to shape a healthy physique and create a healthy physical and mental development through exercise.

In an article, Family Education is the Foundation, Cai Yuanpei, who is a scholar, clearly pointed out the importance of athletic ability to shape physical health. When family education and school education go hand in hand, parents should teach them the rules of appellation as well as the choice of knowledge and communication; it is necessary to take care of their physical health, cultivate a lively nature, and form a new development ${ }^{[1]}$. In How to Be Worthy of Being a Modern Student, it has been proposed that the first thing that a modern student should do is to cultivate the "lion's physical strength" and abandon the "weak literati" image. He believes that the only way to improve the physical strength of Chinese students is to maintain healthy physical fitness ${ }^{[2]}$. Tao Xingzhi, who is also a scholar, emphasized on cultivating students' athletic ability countless times in his article. In his article, Creative Education for Children, it stated that proper nutrition is the physical and psychological needs of children to free their hands ${ }^{[3]}$. In Several Practical Issues of Modern Education, Tao Xingzhi mentioned that principals and teachers at primary schools should have a healthy body and the skills of a farmer ${ }^{[4]}$. It can be appreciated that physical health is the starting point for education, and it is the unanimous expectation of scholars to train people's exercise capacity to promote a sound development of education.

\subsubsection{From the perspective of survival and health}

The cultivation of construction ability mainly begins from practical skills and operational application skills. It is the strive to cultivate people's creativity and construction ability through practical methods. Its cultivation is reflected in a literature by Chen Heqin, Chen's Children's Living Teaching Aids; it was mentioned that the use of bamboo circles, puppet show construction, puppet production, building blocks, 
puzzles, etc. emphasize on construction through children's hands-on operation ${ }^{[5]}$. Other than that, Cai Yuanpei also put forward his thoughts on capacity-building; in My Experience in Education, it was mentioned that it is important to advocate the implementation of the education of omnipotence with both hands and emphasize the view that children's free reading ability must be learned through free contact with things ${ }^{[6]}$. In addition, Tao Xingzhi stated in his article, Popular Education, "You must know that you have the capacity to move in order to gain new knowledge." In the Road to Popularization of Modern Education, the concept of "doing on one side and investigating on the other side" is promoted to ensure capacitybuilding ${ }^{[7]}$. It can be seen that in terms of capacity-building, scholars have advocated that construction comes first and theory supplements; with the two supporting one another, the educational result of integration can be achieved.

\subsubsection{From the perspective of knowledge and skills}

The learning of basic knowledge refers to possessing a certain degree of knowledge, which includes the ability to read and write, the ability to recite, and the ability to express language. In National Dilemma Education, Tao Xingzhi suggested the learning of new pinyin characters and writing tools, thus making it easier to read and write ${ }^{[8]}$. The Breakthrough of Universal Education proposed the idea of learning basic cultural knowledge, pursuing quantity and quality, as well as realizing mass education ${ }^{[9]}$.

The cultivation of research skills includes scientific inquiry skills and academic research concentration. Tao Xingzhi put forward an initiative to improve scientific research in the National Presentation Conference ${ }^{[10]}$. He believes that people are suffering because of the lack of education, especially scientific education. Moreover, in The Breakthrough of Universal Education, it has been proposed that "the dark mind should use the light of science to enlighten it." It can be appreciated that scientific inquiry was also the main focus of scholars during the Republic of China.

\subsection{Pursuit of spiritual value}

\subsubsection{Moral consciousness}

It mainly includes two aspects: equality awareness and fairness awareness.

In terms of the awareness of equality, Huang Yanpei, a scholar, mentioned in Anhui Investigation Diary that nothing is too different from each other, and the purpose of being equal to the people of the Republic is no less important.

In terms of fairness awareness, Chen Heqin expressed in Living Education, "Different people have different groups; they all teach in accordance with their aptitude and have equal opportunities ${ }^{[11]}$."

On the whole, the understanding of moral consciousness by scholars is that the maintenance of moral consciousness requires citizens to earnestly fulfill the spirit of equality, fairness, and consciousness in order to prepare for the creation of a better society together.

\subsubsection{Aesthetic value}

Feeling beauty, appreciating beauty, and creating beauty are the trilogy of aesthetic value. The scholars' understanding of aesthetic value is discussed below.

In Cai Yuanpei's article, The Origin of Fine Arts, the objects of fine arts were discussed systematically, including static fine arts images and dynamic fine arts music; the discussion expanded the stereotyped definition of fine arts and expounded the intrinsic value as well as characteristics of fine arts ${ }^{[12]}$. 


\subsection{Cultivate people with social responsibility}

\subsubsection{Collective consciousness}

In view of the current tasks of life education, Tao Xingzhi mentioned that the power of a group is greater than the power of an individual. He stated, "What children need most is collective, cooperation, and sincere solidarity." It can be said that the collective consciousness advocated by scholars is to communicate people's thoughts and lead people to have a common mission through the cultivation of collective consciousness as well as the habits, beliefs, motives, interests, and other cultural psychology that people have formed through long-term practice. The sense of belonging and identity gradually strengthens the team spirit and produces a strong cohesion.

\subsubsection{Sense of responsibility}

In order to achieve national rejuvenation, Huang Yanpei put forward the requirement that "everyone needs to take responsibility." In an article, Income from School for 40 Years, the issue of the types of responsibilities that should be dealt with is discussed.

Cai Yuanpei mentioned the division of labor between "national responsibility, China's responsibility, and social responsibility" in a literature, My Experience in Education ${ }^{[6]}$. It can be seen that an individual's sense of responsibility toward the society is the foundation of a healthy personality and the guarantee of social stability.

\subsection{Cultivate people with national consciousness}

\subsubsection{Patriotism}

Tao Xingzhi clearly advocated the idea of "arousing the people to save the country" in terms of national disaster education and put forward the idea of "national democracy, freedom and equality, and the integrity of the Chinese nation's territorial sovereignty" as the Shanghai National Disaster Education Program slogan.

\subsubsection{National defense awareness}

Huang Yanpei introduced the concept of "national defense" in Anhui Investigation Diary [13]. In the Republic of China Education Policy, it clearly states that "winning in wartime is the sacred task of educators." The country is defenseless, and the people are defenseless and uneasy. It is enough to see that stopping armed subversion as well as defending the sovereignty, unity, territorial integrity, and security of the country reflect the country's unchanging persistence.

\section{Conclusion}

Generally speaking, based on the literatures by education scholars during the Republic of China, there are several insights for the country.

(1) Cultivate people with universal applicability.

Education is for all members of the society. Therefore, the establishment of educational goals should be broad and universal, with common requirements for the growth and development of the masses as well as professional requirements for people from all walks of life, so that the goals of education can be implemented. 
(2) Cultivate effective people.

This refers to training people who can effectively engage in various activities under certain social environmental conditions. The implementation of educational goals depends on the implementation of educational activities, and the conceptualization of effective educational activities is inseparable from effective activists. Therefore, any measures to cultivate effective activists should be included in the requirements of the education purpose.

(3) Training people to promote the development of socialism with Chinese characteristics.

"Humanization of education," "quality education," "cultivating students' core literacy," and "cultivating people with comprehensive development of morality, intelligence, and physical beauty" have always been advocated by the country. Therefore, progressing in the path of social development with Chinese characteristics and establishing the confidence of socialism with Chinese characteristics are the most important aspects.

\section{Disclosure statement}

The author declares that there is no conflict of interest.

\section{References}

[1] Cai Y, 1933, Family Education is the Foundation. Modern Parents, (01): 9-10.

[2] Cai Y, 1930, How to Be Worthy of Being a Modern Student. Modern Student, (01): 3-5.

[3] Tao X, 1944, Creative Education for Children. Modern Women, (04): 2-5.

[4] Tao X, 1935, Several Practical Problems of Modern Education. New Trends in Education, (04): 11-19.

[5] Chen H, 1942, Chen's Living Teaching Aids for Children. Educational Research, (100): 67-76.

[6] Cai Y, 1940, My Experience in Education. Education Newsletter Weekly, (14): 14-16.

[7] Tao X, 1949, Road to Popularization of Modern Education. Northeast Education, (04): 8.

[8] Tao X, 1936, National Dilemma Education. New Youth, (03): 2-3.

[9] Tao X, 1935, The Breakthrough of Universal Education. Life Education, (03): 85-88.

[10] Tao X, 1939, National Propaganda Conference. Wartime Education, (04): 1-2.

[11] Chen H, 2012, Living Education - Chen Heqin Educational Thought (Chinese Edition), Nanjing Normal University Press, 1-299.

[12] Cai Y, 1920, The Origin of Fine Arts. Trendy, (02): 1-22.

[13] Zhuang J, Zeng Y, 2021, Sorting and Publishing of Modern History Materials, in Contemporary Studies on Modern Chinese History II, Routledge. 